\title{
Sorting nexin 24 genetic variation associates with coronary artery aneurysm severity in Kawasaki disease patients
}

Ying-Ju Lin ${ }^{1,2^{*}}$, Jeng-Sheng Chang ${ }^{3}$, Xiang Liư ${ }^{4}$, Ting-Hsu Lin' ${ }^{1}$, Shao-Mei Huang ${ }^{1}$, Chiu-Chu Liao ${ }^{1}$, Cheng-Wen Lin ${ }^{5}$, Wen- Kuei Chien ${ }^{6,7}$, Jin-Hua Chen ${ }^{6,7}$, Jer-Yuarn Wu ${ }^{2,8}$, Chien-Hsiun Chen ${ }^{2,8}$, Li-Ching Chang ${ }^{8}$, Hsinyi Tsang $^{9}$, Kuan-Teh Jeang ${ }^{4}$, Chia-Yen Chen ${ }^{10}$ and Fuu-Jen Tsai ${ }^{1,2,11^{*}}$

\begin{abstract}
Background: The sorting nexin (SNX) family is involved in endocytosis and protein trafficking and plays multiple roles in various diseases. The role of SNX proteins in Kawasaki disease (KD) is not known. We attempted to test whether genetic SNX variation associates with the risk of coronary artery aneurysm (CAA) formation in KD.

Methods and results: Chi-square tests were used to identify SNX24 genetic variants associated with KD susceptibility and CAA formation in KD; models were adjusted for fever duration and time of first administration of intravenous immunoglobulin. We obtained clinical characteristics and genotypes from KD patients (76 with CAA and 186 without CAA) in a population-based retrospective $K D$ cohort study $(n=262)$. Clinical and genetic factors were associated with CAA formation in KD. In addition, endothelial cell inflammation was evaluated. Significant correlation was observed between KD with CAA complications and the rs28891 single-nucleotide polymorphism in SNX24. Patients with CC + CT genotypes had lesser CAA complications. In lipopolysaccharide-treated human umbilical vein endothelial cells, siRNA knockdown of SNX24 significantly decreased gene expression of the proinflammatory cytokines IL-1 beta, IL-6, and IL-8.
\end{abstract}

Conclusions: Polymorphisms in SNX24 may be used as genetic markers for the diagnosis and prognosis of CAA formation in KD.

Keywords: Kawasaki disease, Coronary artery aneurysm, Sorting nexin 24, Polymorphism

\section{Background}

Kawasaki disease (KD) is an acute and systemic vasculitis in children under 5 years old [1-5]. It is believed to be caused by infectious agents, host immune dysregulation, and genetic susceptibility. During the acute stage of $\mathrm{KD}$, activation of vascular endothelial cells and increased serum levels of proinflammatory cytokines lead to inflammation and injury of blood vessels [6-8]. The vascular inflammation may induce the development of aneurysms and cardiac complications. Complications in coronary artery aneurysms (CAA) make KD one of the leading causes of acquired cardiovascular diseases in

\footnotetext{
* Correspondence: yjlin.kath@gmail.com; d0704@mail.cmuh.org.tw 'Department of Medical Research, China Medical University Hospital, Taichung, Taiwan

${ }^{2}$ School of Chinese Medicine, China Medical University, Taichung, Taiwan Full list of author information is available at the end of the article
}

childhood. Until now, the pathological mechanism of CAA formation in KD has not been fully elucidated.

The sorting nexin (SNX) family of proteins consists of a diverse group of cytoplasmic or membrane-associated molecules that are characterized by the presence of a phospholipid-binding motif, the phox-homology (PX) domain, and are involved in endocytosis and protein trafficking $[9,10]$. The presence of a PX domain is the defining characteristic of this family and has been shown to bind various phosphatidylinositol phosphates (PtdInsPs) [11,12]. This domain is thought to lead these proteins to specialized membrane domains with specific phospholipids [13]. Sorting nexins have been associated with various diseases, including tumorigenesis, inflammation, pathogen infection, and Alzheimer disease [14-19]. The role of SNX proteins in endothelial cell injury and inflammation and their 
correlation with cardiovascular diseases such as KD remain to be elucidated.

To this end, we screened variants of 10 genes that encode SNX proteins associated with KD with CAA formation. The genes studied were SNX17, SNX3, SNX10, SNX16, SNX22, SNX29, SNX20, SNX11, SNX21, and SNX24. In this study, $262 \mathrm{KD}$ patients (76 with CAA and 186 without CAA) were evaluated for clinical characteristics, the extent of aneurysm formation, and SNX24 genotype. We observed that genetic variation in SNX24 was associated with CAA formation in KD.

\section{Results}

\section{Genotype frequencies of SNX24 polymorphisms}

A total of $262 \mathrm{KD}$ patients and 1107 unrelated healthy control individuals were included in this study. The genotypes of the 9 genetic polymorphisms were identified by a custom-designed genotyping method [20]. The genotype frequencies of these polymorphisms are shown in Table 1. The KD patients did not differ from the control individuals with respect to the genotype frequencies of these polymorphisms (Table 1).

SNX24 single-nucleotide polymorphism rs28891 is associated with CAA formation in KD

Subsequently, we genotyped the $262 \mathrm{KD}$ patients for SNX24 single-nucleotide polymorphisms (SNPs) (Table 2). The genetic location of SNX24 is shown in Figure 1; the frequency of genotyping success was $>99 \%$. The linkage disequilibrium (LD) structure of this region was also established and was found to consist of a single haplotype block.

Table 1 Genotype distributions of SNX24 gene SNPs in Taiwanese KD patients and controls

\begin{tabular}{|c|c|c|c|c|c|c|c|c|c|}
\hline \multirow[t]{2}{*}{ SNP } & \multirow[t]{2}{*}{ Chromosome } & \multirow[t]{2}{*}{ Cytoband } & \multirow[t]{2}{*}{ Physical position } & \multirow[t]{2}{*}{ Nearest genes } & & \multirow{2}{*}{$\begin{array}{l}\text { Controls } \\
\text { No. (\%) }\end{array}$} & \multicolumn{3}{|c|}{ KD patients } \\
\hline & & & & & & & No. (\%) & $p$ value & Odds ratio $(95 \% \mathrm{Cl})$ \\
\hline \multirow[t]{3}{*}{ rs154507 } & 5 & $\mathrm{q} 23.2$ & 122228806 & SNX24 & GG & $146(13.2)$ & $38(14.5)$ & 0.755 & $1.17(0.76-1.78)$ \\
\hline & & & & & GC & $553(50.0)$ & $133(50.8)$ & & $1.08(0.80-1.45)$ \\
\hline & & & & & $\mathrm{CC}$ & $408(36.8)$ & $91(34.7)$ & & 1 \\
\hline \multirow[t]{3}{*}{ rs 27740} & 5 & $\mathrm{q} 23.2$ & 122232671 & SNX24 & $\pi$ & $156(14.1)$ & $38(14.5)$ & 0.867 & $1.08(0.71-1.65)$ \\
\hline & & & & & TA & $547(49.4)$ & $133(50.8)$ & & $1.08(0.80-1.45)$ \\
\hline & & & & & AA & $404(36.5)$ & $91(34.7)$ & & 1 \\
\hline \multirow[t]{3}{*}{ rs26371 } & 5 & $\mathrm{q} 23.2$ & 122234424 & $S N \times 24$ & $\pi$ & $217(19.6)$ & $56(21.4)$ & 0.690 & $1.19(0.80-1.76)$ \\
\hline & & & & & $\mathrm{TC}$ & $573(51.8)$ & $137(52.3)$ & & $1.10(0.80-1.51)$ \\
\hline & & & & & $\mathrm{CC}$ & $317(28.7)$ & $69(26.3)$ & & 1 \\
\hline \multirow[t]{3}{*}{ rs6595415 } & 5 & $\mathrm{q} 23.2$ & 122234657 & SNX24 & $\pi$ & $151(13.6)$ & $38(14.5)$ & 0.842 & $1.12(0.73-1.70)$ \\
\hline & & & & & $\mathrm{TC}$ & $530(47.9)$ & $128(48.9)$ & & $1.07(0.80-1.44)$ \\
\hline & & & & & $\mathrm{CC}$ & $426(38.5)$ & 96 (36.6) & & 1 \\
\hline \multirow[t]{3}{*}{ rs17149732 } & 5 & $\mathrm{q} 23.2$ & 122249811 & SNX24 & $\pi$ & $146(13.2)$ & $37(14.1)$ & 0.784 & $1.14(0.74-1.73)$ \\
\hline & & & & & $\mathrm{TG}$ & $530(47.9)$ & $129(49.2)$ & & $1.09(0.81-1.46)$ \\
\hline & & & & & GG & $430(38.9)$ & 96 (36.6) & & 1 \\
\hline \multirow[t]{3}{*}{ rs17149748 } & 5 & $\mathrm{q} 23.2$ & 122295266 & $S N X 24$ & $\mathrm{CC}$ & 150 (13.6) & $37(14.1)$ & 0.710 & $1.13(0.74-1.72)$ \\
\hline & & & & & $\mathrm{CT}$ & $532(48.1)$ & $131(50.0)$ & & $1.13(0.84-1.51)$ \\
\hline & & & & & $\Pi$ & $425(38.4)$ & 93 (35.5) & & 1 \\
\hline \multirow[t]{3}{*}{ rs1038078 } & 5 & q23.2 & 122309550 & SNX24 & AA & $147(13.3)$ & $37(14.1)$ & 0.676 & $1.15(0.75-1.76)$ \\
\hline & & & & & $A G$ & $526(47.5)$ & 130 (49.6) & & $1.13(0.84-1.51)$ \\
\hline & & & & & GG & $434(39.2)$ & 95 (36.3) & & 1 \\
\hline \multirow[t]{3}{*}{ rs28891 } & 5 & $\mathrm{q} 23.2$ & 122311523 & $S N \times 24$ & $\mathrm{CC}$ & $187(16.9)$ & $47(17.9)$ & 0.836 & $1.12(0.75-1.67)$ \\
\hline & & & & & $\mathrm{CT}$ & $554(50.1)$ & $133(50.8)$ & & $1.07(0.79-1.45)$ \\
\hline & & & & & $\Pi$ & $366(33.1)$ & $82(31.3)$ & & 1 \\
\hline \multirow[t]{3}{*}{ rs6595423 } & 5 & $q 23.2$ & 122341433 & SNX24 & $\mathrm{CC}$ & $144(13.0)$ & $36(13.7)$ & 0.667 & $1.14(0.75-1.75)$ \\
\hline & & & & & $\mathrm{CT}$ & $524(47.3)$ & $130(49.6)$ & & $1.13(0.85-1.52)$ \\
\hline & & & & & $\Pi$ & 439 (39.7) & 96 (36.6) & & 1 \\
\hline
\end{tabular}

SNX24, sorting nexin 24; SNP, single nucleotide polymorphism; $\mathrm{Cl}$, confidence interval. 
Table 2 Summary of the SNPs associated with the CAA formation in Taiwanese Kawasaki disease

\begin{tabular}{|c|c|c|c|c|c|c|c|c|c|}
\hline SNP & Chromosome & Cytoband & Physical position & Nearest genes & & $\begin{array}{c}\text { CAA- } \\
\text { No. (\%) }\end{array}$ & $\begin{array}{c}\text { CAA+ } \\
\text { No. (\%) }\end{array}$ & $p$ value & Odds ratio $(95 \% \mathrm{Cl})$ \\
\hline \multirow[t]{3}{*}{ rs154507 } & 5 & q23.2 & 122228806 & SNX24 & GG & $24(12.9)$ & $14(18.4)$ & 0.234 & $1.94(0.86-4.41)$ \\
\hline & & & & & GC & $92(49.5)$ & $41(54.0)$ & & $1.49(0.81-2.74)$ \\
\hline & & & & & CC & $70(37.6)$ & $21(27.6)$ & & 1 \\
\hline \multirow[t]{3}{*}{ rs 27740} & 5 & q23.2 & 122232671 & SNX24 & $\pi$ & $24(12.9)$ & $14(18.4)$ & 0.234 & $1.94(0.86-4.41)$ \\
\hline & & & & & TA & $92(49.5)$ & $41(54.0)$ & & $1.49(0.81-2.74)$ \\
\hline & & & & & $\mathrm{AA}$ & $70(37.6)$ & $21(27.6)$ & & 1 \\
\hline \multirow[t]{3}{*}{ rs 26371} & 5 & $q 23.2$ & 122234424 & SNX24 & $\pi$ & $44(23.7)$ & $12(15.8)$ & 0.123 & $0.45(0.20-1.01)$ \\
\hline & & & & & $\mathrm{TC}$ & $99(53.2)$ & $38(50.0)$ & & $0.63(0.34-1.17)$ \\
\hline & & & & & CC & $43(23.1)$ & $26(34.2)$ & & 1 \\
\hline \multirow[t]{3}{*}{ rs6595415 } & 5 & $q 23.2$ & 122234657 & $S N \times 24$ & $\pi$ & $23(12.4)$ & $15(19.7)$ & 0.198 & $2.07(0.93-4.61)$ \\
\hline & & & & & $\mathrm{TC}$ & $90(48.4)$ & $38(50.0)$ & & $1.34(0.73-2.45)$ \\
\hline & & & & & CC & $73(39.2)$ & $23(30.3)$ & & 1 \\
\hline \multirow[t]{3}{*}{ rs171499732 } & 5 & q23.2 & 122249811 & SNX24 & $\pi$ & $23(12.4)$ & $14(18.4)$ & 0.261 & $1.93(0.86-4.36)$ \\
\hline & & & & & $\mathrm{TG}$ & $90(48.4)$ & $39(51.3)$ & & $1.38(0.75-2.51)$ \\
\hline & & & & & GG & $73(39.2)$ & $23(30.3)$ & & 1 \\
\hline \multirow[t]{3}{*}{ rs17149748 } & 5 & $\mathrm{q} 23.2$ & 122295266 & SNX24 & CC & $23(12.4)$ & $14(18.4)$ & 0.242 & $1.96(0.87-4.45)$ \\
\hline & & & & & $\mathrm{CT}$ & $91(49.2)$ & $40(52.6)$ & & $1.42(0.77-2.60)$ \\
\hline & & & & & $\Pi$ & $71(38.4)$ & $22(29.0)$ & & 1 \\
\hline \multirow[t]{3}{*}{ rs1038078 } & 5 & q23.2 & 122309550 & SNX24 & AA & $23(12.4)$ & $14(18.4)$ & 0.283 & $1.91(0.84-4.30)$ \\
\hline & & & & & $A G$ & $91(48.9)$ & $39(51.3)$ & & $1.34(0.74-2.45)$ \\
\hline & & & & & GG & $72(38.7)$ & $23(30.3)$ & & 1 \\
\hline \multirow[t]{3}{*}{ rs28891 } & 5 & q23.2 & 122311523 & SNX24 & CC & $39(21.0)$ & 8 (10.6) & 0.006 & $0.29(0.12-0.70)$ \\
\hline & & & & & $C \mathrm{~T}$ & $99(53.2)$ & $34(44.7)$ & & $0.48(0.27-0.87)$ \\
\hline & & & & & $\pi$ & $48(25.8)$ & $34(44.7)$ & & 1 \\
\hline \multirow[t]{3}{*}{ rs6595423 } & 5 & q23.2 & 122341433 & SNX24 & CC & $23(12.4)$ & $13(17.1)$ & 0.322 & $1.79(0.79-4.10)$ \\
\hline & & & & & $C T$ & $90(48.4)$ & $40(52.6)$ & & $1.41(0.78-2.57)$ \\
\hline & & & & & $\pi$ & $73(39.2)$ & $23(30.3)$ & & 1 \\
\hline
\end{tabular}

SNX24, sorting nexin 24; SNP, single nucleotide polymorphism; CAA, Coronary artery aneurysm; Cl, confidence interval. p-values were obtained by chi-square test.

Bold, emphasizing statistical significance was considered as $p$ value $<0.05$.

Genotype and genotype frequency data for all 9 SNPs are shown in Table 2. A statistically significant difference was observed for the SNX24 (rs28891) genetic variant ( $p=$ 0.006). The frequencies of individuals carrying the $\mathrm{CC}$ and CT genotypes of SNX24 (rs28891) were 10.6\% and 44.7\%, respectively, for CAA-positive individuals. The frequencies of the $\mathrm{CC}$ and $\mathrm{CT}$ genotypes were significantly lower in $\mathrm{KD}$ individuals with CAA formation (CC genotype: odds ratio $(\mathrm{OR})=0.29,95 \%$ confidence interval $(\mathrm{CI})=0.12-0.70$; CT genotype: odds ratio $=0.48,95 \% \mathrm{CI}=0.27-0.87$ ) compared to $\mathrm{KD}$ individuals without CAA formation.

\section{Associating variation in the SNX24 SNP rs28891 to CAA} formation in KD by using logistic regression analysis To determine the genetic role of $S N X 24$, we used logistic regression analysis to rule out the clinical potential factor effects in CAA formation in KD. As shown in Table 3, after adjusting for these factors [21-25], there was a significant association between the SNX24 SNP rs28891 and the incidence of KD with CAA. Specifically, significant correlations were found between KD with CAA formation and the CC+CT genotypes of the SNX24 SNP rs28891 (model adjusted by fever duration: odds ratio $=0.41,95 \% \mathrm{CI}=0.25-0.75, p=0.003$; model adjusted by time of first administration of intravenous immunoglobulin (IVIG): odds ratio $=0.42$, $95 \% \mathrm{CI}=0.25-0.75, p=0.002$ ).

The genotype distributions of rs28891 in relation to CAA severity in the study population are also shown in Figure 2. As shown in Figure 2, there were lower percentages of the SNX24 SNP genotypes CC + CT in patients with CAA formation compared to patients with 


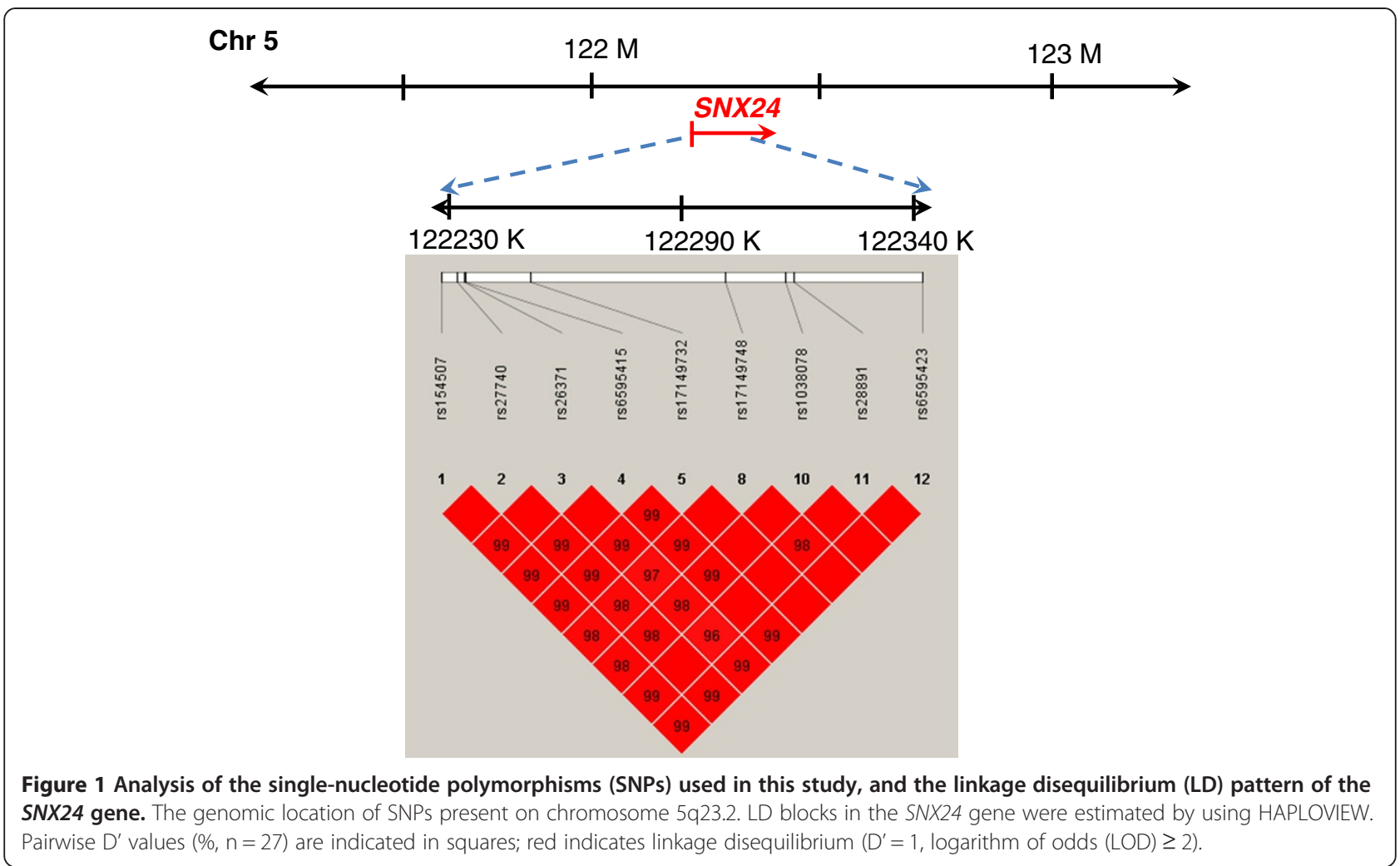

the TT genotype; this suggests that patients with the $\mathrm{CC}+$ CT genotypes were correlated with less severe CAA complications.

Inhibition of IL-1 beta, IL-6, and IL-8 mRNA expression by downregulation of SNX24 in lipopolysaccharide-treated human umbilical vein endothelial cells

To evaluate the effect of SNX24 on endothelial cell inflammation, we used lipopolysaccharide (LPS) (an integral part of the outer membrane of gram-negative bacteria) as a pathogenic stimulus. Human umbilical vein endothelial cells (HUVECs) were transfected with short interfering RNAs (siRNAs) and then were treated with LPS. The proinflammatory cytokine expression in the endothelial cells was then analyzed by using realtime qPCR assays (Figure 3). HUVECs were transiently transfected with siRNAs targeting SNX24 (siSNX24), and the effect was assessed (Figure 3A). Compared to siNC-transfected HUVECs, cells transfected with siSNX24 resulted in a significant decrease in SNX24 mRNA expression (Figure 3A). In addition, siRNAtransfected cells were then exposed to LPS. As shown in Figure $3 \mathrm{~B}$, treatment of HUVECs with LPS significantly increased the expression of $I L-1$ beta, $I L-6$, and $I L-8$. siRNA knockdown of SNX24 significantly decreased gene expression of the proinflammatory cytokines IL-1 beta, IL-6, and IL-8, suggesting that SNX24 may regulate endothelial cell inflammation.

\section{Discussion}

To the best of our knowledge, no study to date has investigated the possible association of SNX family genes and the CAA formation in Kawasaki disease. In this study, we screened genetic variants of 9 SNX genes in relation to $\mathrm{KD}$ with $\mathrm{CAA}$ formation and identified a SNP in SNX24 that correlates with the development of CAA formation in Taiwanese children of Han Chinese ethnic background with KD. We observed a significant association between the SNX24 SNP and the occurrence of CAA in KD patients by using a logistic regression analysis. The frequencies of the CC and CT genotypes of SNX24 SNP rs28891 were lower in the group with KD and CAA than in the group with KD but without CAA. Cell inflammatory activity was inhibited in siSNX24treated cells. Our results suggest that polymorphisms in SNX24 may be used as genetic markers for the diagnosis and prognosis of the CAA formation in $\mathrm{KD}$.

Our results showed that the increased CAA formation in KD was associated with clinical risk factors, including fever duration and the time of administering the first IVIG treatment (days after the first incidence of fever). These findings also correspond with those reported previously in patients with KD [21-25]. Longer fever duration and the delay of IVIG treatment seem to be risk factors for the development of CAA in patients with KD. Prolonged fever duration suggests a state of longer and more severe inflammation. Endothelial cell injury and 
Table 3 Association of SNX24 genetic variants with CAA formation risk in Taiwanese Kawasaki disease by logistic regression analysis

\begin{tabular}{|c|c|c|c|}
\hline SNX24 genetic variants & Odds ratio & $95 \% \mathrm{Cl}$ & $p$ value \\
\hline \multicolumn{4}{|c|}{ Adjusted by fever duration (days) } \\
\hline rs154507 & 1.90 & $0.88-2.83$ & 0.046 \\
\hline rs27740 & 1.90 & $0.88-2.83$ & 0.046 \\
\hline rs26371 & 0.60 & $0.32-1.04$ & 0.105 \\
\hline rs6595415 & 1.74 & $0.84-2.64$ & 0.077 \\
\hline rs17149732 & 1.74 & $0.84-2.64$ & 0.077 \\
\hline rs17149748 & 1.83 & $0.86-2.72$ & 0.057 \\
\hline rs1038078 & 1.71 & $0.82-2.58$ & 0.087 \\
\hline rs28891 & 0.41 & $0.25-0.75$ & 0.003 \\
\hline rs6595423 & 1.74 & $0.84-2.64$ & 0.077 \\
\hline \multicolumn{4}{|c|}{ Adjusted by 1st IVIG used (days after the first date with fever) } \\
\hline rs154507 & 1.61 & $0.88-2.83$ & 0.114 \\
\hline rs27740 & 1.61 & $0.88-2.83$ & 0.114 \\
\hline rs 26371 & 0.57 & $0.32-1.04$ & 0.059 \\
\hline rs6595415 & 1.52 & $0.84-2.64$ & 0.152 \\
\hline rs17149732 & 1.52 & $0.84-2.64$ & 0.152 \\
\hline rs17149748 & 1.57 & $0.86-2.72$ & 0.127 \\
\hline rs1038078 & 1.50 & $0.82-2.58$ & 0.171 \\
\hline rs28891 & 0.42 & $0.25-0.75$ & 0.002 \\
\hline rs6595423 & 1.52 & $0.84-2.64$ & 0.152 \\
\hline
\end{tabular}

SNX24, sorting nexin 24; IVIG, Intravenous immunoglobulin; CAA, Coronary artery aneurysm; Cl, confidence interval.

A logistic regression model was performed by using the indicated predictors including fever duration (days) or 1st IVIG used time (days after the first date with fever).

Bold, emphasizing statistical significance was considered as $p$ value $<0.006(0.05 / 9)$.

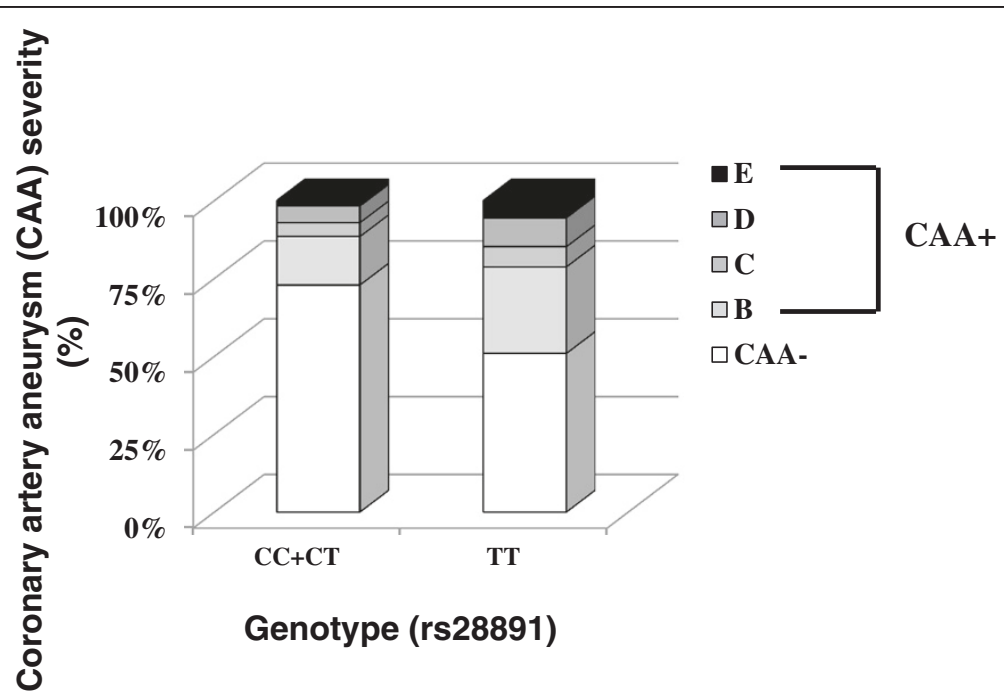

Figure 2 Genotype distribution (SNX24 rs28891) in relation to coronary artery aneurysm (CAA) severity in the study population. CAA severity grade: CAA- indicates patients with no complication; CAA + B grade indicates patients with CAAs at the beginning but that are in remission within 2 months; $C A A+C$ grade indicates patients with CAAs that persist for 2 months but that are in remission within 6 months; CAA + D grade indicates patients with CAAs that persist for 6 months; CAA + E grade indicates patients with giant CAAs ( $\geq 8$ mm) or severe stenosis or occlusion. 


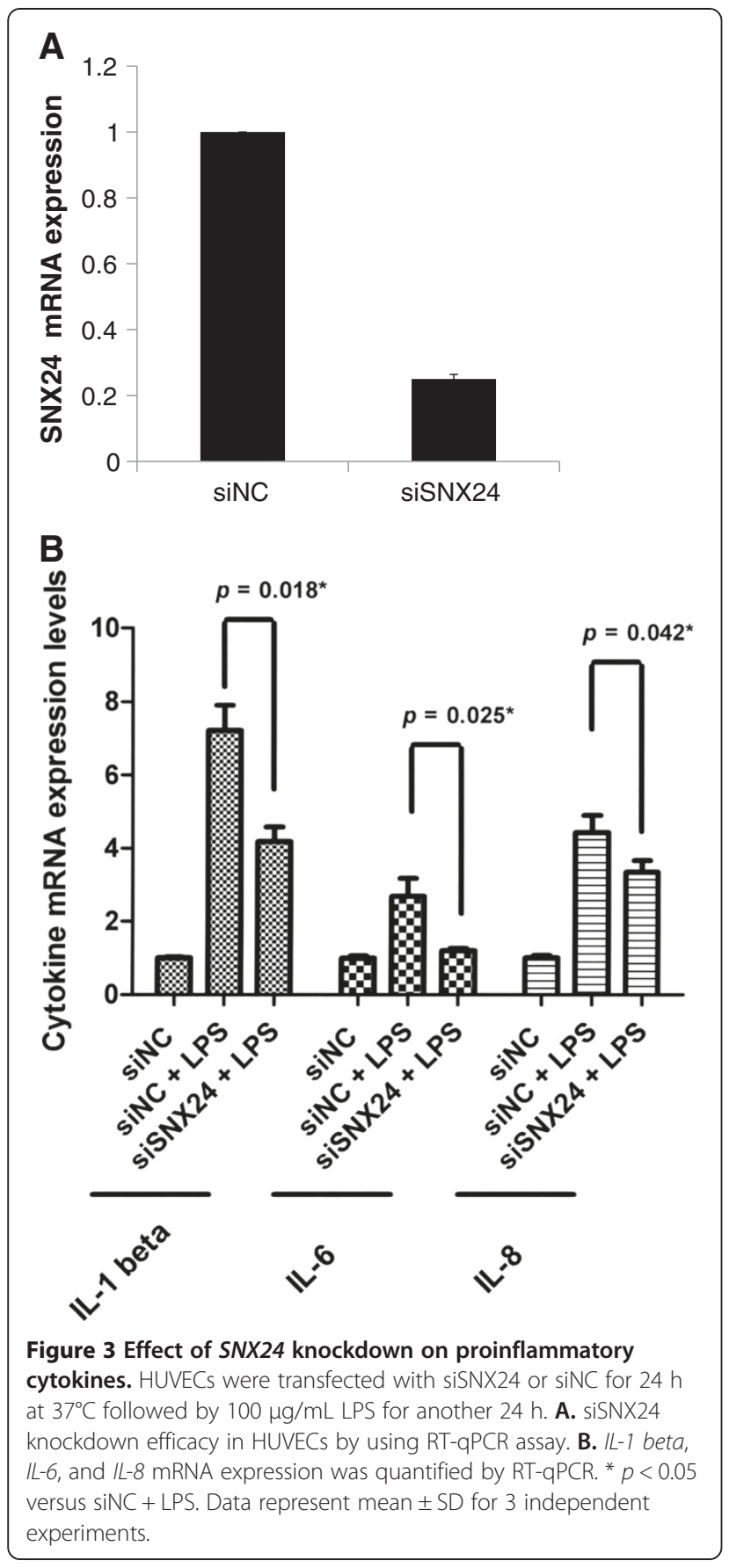

inflammations are known to be the main mechanisms in the development of KD [4]. When endothelial cells are stimulated with pathogenic mediator LPS, inflammatory signals are triggered, which increase permeability and leukocyte recruitment [26]. KD is a multi-systemic disorder with immune-mediated vasculitis and is very likely to influence CAA complications.

This genetic association study showed that significant associations between KD with CAA formation and the SNX24 SNP rs28891 were still observed by using logistic regression analysis. The frequency of genotypes with 1 or 2 copies of the $\mathrm{C}$ allele were lower in $\mathrm{KD}$ patients with CAA formation. This SNP is located in the intron region of $S N X 24$. Intronic SNPs may have an impact on splicing efficiency, the stability of the transcribed mRNA, and enhancer activity [27]. Change in the secondary structure of the pre-mRNA by a nucleotide substitution may influence splicing and mRNA formation [28,29]. In addition, the SNP we identified (rs28891) exhibited LD with the SNP (rs1038078) (Additional file 1: Table S1; $\left.\mathrm{D}^{\prime}=1\right)$. SNX24 expression has been shown to be significantly associated with the SNP (rs1038078) $(p=0.04329)$ in the Han Chinese population (http://app3.titan.uio.no/ biotools/tool.php?app=snpexp). Therefore, it is likely that the CC and CT genotypes of the SNX24 gene polymorphism may be associated with transcript abundance. To further investigate the functional consequences of SNX24 polymorphism, we first investigated the correlation between the SNP rs28891 genotypes and SNX24 expression (Additional file 2: Figure S1). We measured SNX24 mRNA levels by real-time quantitative PCR in peripheral blood mononuclear cells. As shown, the major allele homozygotes (TT genotype) tended to express higher levels of $S N X 24$ than did the other individuals with $\mathrm{CC}+\mathrm{CT}$ genotype $(p=0.035$; Additional file 2 : Figure S1). Our results also suggest that the frequencies of CC and CT genotypes were significantly lower in KD with CAA formation compared to those in $\mathrm{KD}$ without CAA formation. A possible explanation is that the SNX24 protein expression levels are involved in inflammations of vascular endothelial cells and the consequences of CAA complications in KD patients.

Endothelial cell injury and inflammations are known to be the main mechanisms in the development of KD [4]. When endothelial cells are stimulated with pathogenic mediator LPS, the stimulated cells trigger inflammatory signals to increase permeability and leukocyte recruitment [26]. In this study, we used this LPSinduced endothelial cell inflammation model and showed, for the first time, that SNX24 may regulate endothelial cell inflammation by interfering with IL-1 beta, IL-6, and IL- 8 expressions. SNX24 is located on chromosome $5 \mathrm{q} 23.2$. It is preferentially expressed in platelets and blood plasma (http://www.genecards.org/cgibin/carddisp.pl?gene=SNX24\&search=SNX24\#diseases). Estrogen has been found to significantly upregulate the expression of SNX24 in certain breast cancer cell lines, suggesting that it has a role in tumorigenesis [30]. Conversely, SNX family proteins have been linked to trafficking and cell surface presentation of adhesion molecules on leucocytes, platelets, and endothelial cells. SNX family proteins might be involved in vasculitis and endothelial cell pathogenesis. Another member in the SNX family, SNX17, was identified as a P-selectin-interacting protein. It can decrease the 
degradation of P-selectin in lysosomes by restricting its transport into late endosomes, thereby affecting leucocyte recruitment [15,31]. The release of chemokines and cytokines by macrophages within injured tissue will initiate a series of events whereby leucocytes are attached to the endothelium [32,33].

We screened genetic variants of 9 genes that encode SNX genes linked to KD with CAA formation (Additional file 1: Table S1). These genes include $S N X 17, S N X 3$, SNX10, SNX16, SNX22, SNX29, SNX20, SNX11, and $S N X 21$. This gene family encodes proteins that belong to a diverse group of cytoplasmic and membraneassociated proteins and are involved in various aspects of endocytosis and protein trafficking through membranous cellular compartments [9]. No significant statistical difference was observed for these SNX genes with respect to $\mathrm{KD}$ with $\mathrm{CAA}$ formation. We only observed a significant association between KD with CAA formation and the SNX24 (rs28891). Therefore, we suggest that this SNX24 genetic variant has a role in CAA formation in KD patients. In addition, in our study of the functional significance of $S N X 24$ in endothelial cell inflammation, we used siRNA knockdown of SNX24 to significantly decrease gene expression of the proinflammatory cytokines of $I L-1$ beta, $I L-6$, and $I L-8$. This is the first study to report that $S N X 24$ is a regulator of vascular inflammation and may be beneficial for many inflammatory diseases associated with endothelial dysfunction.

\section{Methods}

\section{Study subjects}

Unrelated individuals fulfilling the diagnostic criteria of KD ( $n=262$ ) were identified and enrolled in the study from the Department of Pediatrics at China Medical University Hospital in Taichung, Taiwan [21,34-37]. All patients were diagnosed according to KD criteria [21,35], including fever lasting 5 days or more and at least 4 of the following symptoms: (1) changes in extremities (e.g., erythema, edema, or desquamation), (2) bilateral conjunctivitis, (3) polymorphous rash, (4) cervical lymphadenopathy, and (5) changes in the lips or oral cavity (e.g. pharyngeal erythema, dry/ fissured or swollen lips, or "strawberry tongue"). All patients received IVIG treatment and had regular echocardiographic examinations during the 1-year follow-up. The echocardiographic examinations were made during the acute stage, 2 months after onset, 6 months after onset, and once per year thereafter. CAA was identified when either the right or the left coronary artery showed a dilated diameter $\geq 3 \mathrm{~mm}$ in children younger than 5 years of age, or $\geq 4 \mathrm{~mm}$ in older children [38]. Only Han Chinese individuals, who account for $98 \%$ of Taiwanese residents, were recruited. The ethnic background was assigned based on the results of selfreported questionnaires. This study was approved by the Human Studies Committee of China Medical University
Hospital. Written informed consent was obtained from either the parents or the participants.

\section{SNP genotyping}

Nine SNPs located in SNX24 were randomly selected from the identified candidate SNPs that conformed to a set of criteria, by using the HAPLOVIEW software (Figure 1 and Table 2) [39-41]. The selection criteria that were used included a minimum allele frequency of $p>0.05$ in the Han Chinese population, and no deviation from HWE $(p>0.05)$. A summary of information regarding the SNX24 SNPs (location, position, rs number, and genotype) is listed in Table 2. Briefly, genomic DNA was extracted from peripheral blood leukocytes according to standard protocols (Genomic DNA kit; Qiagen, Hilden, Germany). SNPs were genotyped using a custom-designed VeraCode GoldenGate Genotyping Assay System (Illumina, San Diego, CA, USA) [42]; genotyping was performed as described at http://www. illumina.com/.

Primers and probes were designed using the Custom VeraCode GoldenGate Genotyping Assay System software. Multiplex PCRs were performed with 144-plex VeraCode SNP arrays (Illumina) using these samples, and genotype analyses were performed using custom 96plex SAM arrays for 96 samples. Genotype calls were automatically generated using GenCall version 3.1.3. We assessed 8 VeraCode runs individually for intra-plate inconsistencies, such as variation in the intensity of the fluorescence. Genotype cluster plots generated from individual VeraCode and SAM assays were visually inspected for call quality. Plots that appeared to be "unusually" clustered (i.e., those that did not match the predicted spread in terms of software-generated HWE or distance between clusters $[\theta]$ ) were investigated further by confirming the genotype of the selected samples via direct Sanger sequencing. Samples were sequenced using Big Dye Terminator v3.1 (AB, Foster City, CA, USA) according to the manufacturer's guidelines and sequenced using a 3730 genetic analyzer (Life Technologies, Carlsbad, CA, USA).

\section{Analysis of haplotype blocks}

Based on HAPLOVIEW, we used Lewontin's D' to estimate the inter-marker coefficient of LD of patients [41]. The confidence interval of LD was estimated using a resampling procedure and was used to construct haplotype blocks $[43,44]$.

\section{Statistical analysis}

Unless otherwise indicated, data are expressed as the mean \pm SD for continuous variables. The unpaired Student's $t$ test was used to compare groups. Genotypes were obtained by direct counting followed by allele frequency calculations (Table 2). Chi-squared tests were used to identify 
differences in categorical variables, and OR and $95 \% \mathrm{CI}$ were calculated for the factors under consideration. Forward stepwise multivariate regression analyses were also performed to identify factors contributing independently to CAA formation in KD. All statistical analyses were performed using SPSS v12.0 for Windows (IBM, Armonk, NY, USA).

\section{Cells}

HUVECs (BCRC Number: H-UV001) were grown in 90\% GIBCO medium 199 (Life Technologies) with $25 \mathrm{U} / \mathrm{mL}$ heparin (Sigma), $30 \mu \mathrm{g} / \mathrm{mL}$ endothelial cell growth supplement (Millipore) adjusted to contain $1.5 \mathrm{~g} / \mathrm{L}$ sodium bicarbonate $+10 \%$ fetal bovine serum and $100 \mathrm{U} / \mathrm{mL}$ penicillin/ streptomycin.

\section{Short interfering RNA}

siRNAs targeting transcripts for SNX24 (siSNX24: CAGAAAUCCCUUCUAAACAUGUUAG) were purchased from Invitrogen, as was the non-targeting siRNA control (scrambled (siNC: duplex 1, AUGAACGU GAAUUGCUCAA; duplex 2, UAAGGCUAUGAAGA GAUAC; duplex 3, AUGUAUUGGCCUGUAUUAG; duplex 4, UAGCGACUAAACACAUCAA)).

\section{Endothelial cell inflammation assay}

For endothelial cell inflammation assay, HUVECs were aliquoted in 6-well plates. Cells were transfected by either siNC or siSNX24 using Lipofectamine 2000 (Invitrogen). The transfected cells were then treated with $100 \mu \mathrm{g} / \mathrm{mL}$ LPS for another $24 \mathrm{~h}$. Cellular RNA extraction and real-time RT-PCR analyses were performed.

\section{Real-time RT-PCR analyses}

HUVECs transfected by either siNC or siSNX24 were incubated for $36 \mathrm{~h}$ at $37^{\circ} \mathrm{C}$. Cellular RNA isolation was performed using a QIAamp RNA Mini Kit according to the manufacturer's instructions (Qiagen, Valencia, CA, USA). RNA was eluted in $60 \mu \mathrm{L}$ of buffer, and real-time TaqMan RT-PCR assays were used to determine the effects of siSNX24 knock down. The primers used to amplify SNX24 by qPCR were $5^{\prime}$ forward primer: $5^{\prime}$-CGTCCTTTCGCTA TGAAGAGA-3' and 3' reverse primer: 5'-TTCTTCC ATTCATTAGCACTTCTATC-3'. The primers for $I L-1$ beta $\mathrm{qPCR}$ were $5^{\prime}$ forward primer: $5^{\prime}$-tacctgtcctgcgtgttgaa$3^{\prime}$ and $3^{\prime}$ reverse primer: $5^{\prime}$-tctttgggtaattttgggatct- $3{ }^{\prime}$. The primers for $I L-6$ qPCR were $5^{\prime}$ forward primer: $5^{\prime}$-cag gagcccagctatgaact-3' and $3^{\prime}$ reverse primer: $5^{\prime}$-gaaggcag caggcaacac- $3^{\prime}$. The primers for $I L-8$ qPCR were $5^{\prime}$ forward primer: $5^{\prime}$-gagcactccataaggcacaaA-3' and $3^{\prime}$ reverse primer: $5^{\prime}$-atggttccttccggtggt- 3 '. Reverse transcription was performed in a $10-\mu \mathrm{L}$ reaction mixture consisting of $2 \mu \mathrm{L}$ RNA template, $1 \mu \mathrm{L}$ RT primer mix, $1 \mu \mathrm{L}$ dNTP mix (10 $\mathrm{mM}$ of each), and $6 \mu \mathrm{L}$ of RNA/DNAse-free water, at $65^{\circ} \mathrm{C}$ for $5 \mathrm{~min}$. Next, a reaction mixture of $4 \mu \mathrm{L} 5 \times$ MMLV buffer, $0.8 \mu \mathrm{L}$ MMLV enzyme, and 5.2 $\mu \mathrm{L}$ RNA/DNAse-free water was added to each RNA sample. Reverse transcription reactions were performed at $42^{\circ} \mathrm{C}$ for $60 \mathrm{~min}$. cDNA was amplified by $\mathrm{PCR}$ in a $20-\mu \mathrm{L}$ reaction mixture containing $5 \mu \mathrm{L}$ cDNA, $10 \mu \mathrm{L}, 2 \times$ Mastermix, $1 \mu \mathrm{L}$ primer/ probe mix, and $4 \mu \mathrm{L}$ RNA/DNAse-free water. Real-time TaqMan RT-PCR conditions were $95^{\circ} \mathrm{C}$ for $10 \mathrm{~min}, 50 \mathrm{cy}-$ cles of $95^{\circ} \mathrm{C}$ for $10 \mathrm{~s}$, and $60^{\circ} \mathrm{C}$ for $60 \mathrm{~s}$. SNX24 RNA levels were detected using a 7900HT Fast Real-Time PCR System (Life Technologies).

\section{Additional files}

Additional file 1: Table S1. Summary of the SNPS from SNX gene family associated with the CAA formation in Taiwanese Kawasaki disease. Table S2. Haplotype distributions of SNX24 gene SNPS associated with the CAA formation in Taiwanese KD patients. Table S3. Genotype distributions of SNX24 gene SNPS in Taiwanese male and female KD patients. Table S4. Genotype distributions of SNX24 gene SNPs in Taiwanese male KD patients. Table S5. Genotype distributions of SNX24 gene SNPs in Taiwanese female KD patients.

Additional file 2: Figure S1. SNX24 mRNA expression levels in peripheral blood mononuclear cells between the SNX24 SNP (rs28891) genotypes. The relative SNX24 expression was detected by real-time RT-PCR, and expression from individuals with $C C+C T$ genotypes was compared to that from individuals with $T$ genotypes. The relative expression levels were expressed as SNX24 mRNA/ HPRT mRNA ratio. Figure S2. Single nucleotide polymorphisms (SNPs) of the SNX24 gene used in this study. Above and middle: Genomic location of SNPs present on chromosome 5. Down: Non-coding RNAs mapped to the intron 3 of SNX24 gene.

\section{Competing interest}

The authors declare that they have no competing interest.

\section{Authors' contributions}

YJL, JSC, XL and FJT conceived and designed the experiments. THL, SMH, $\mathrm{CCL}, \mathrm{CWL}$ and $\mathrm{HT}$ performed the experiments. WKC and JHC analyzed the data. JSC, JYW, CHC, LCC, KTJ and CYC contributed reagents/materials/ analysis tools. YJL and $\mathrm{XL}$ wrote the manuscript. All authors read and approved the final manuscript.

\section{Acknowledgments}

The authors wish to thank the China Medical University Hospital (CMUH) Department of Pediatrics for administrative assistance. Support for this research was provided by China Medical University (CMU100-S-01), China Medical University Hospital (DMR-102-83), and the Republic of China National Science Council (NSC101-2314-B-039-008-MY3). The research design was approved by the Human Subjects Committee of the Institutional Review Board of CMU Hospital. We also thank Dr. Willy W. L. Hong for technical help and suggestions.

\section{Funding}

Support for this research was provided by CMU (CMU100-S-01), CMUH (DMR-102-83), and the Republic of China National Science Council (NSC1012314-B-039-008-MY3).

\section{Author details}

${ }^{1}$ Department of Medical Research, China Medical University Hospital, Taichung, Taiwan. ${ }^{2}$ School of Chinese Medicine, China Medical University, Taichung, Taiwan. ${ }^{3}$ Department of Pediatrics, China Medical University Hospital, Taichung, Taiwan. ${ }^{4}$ Molecular Virology Section, Laboratory of Molecular Microbiology, National Institute of Allergy and Infectious Diseases, National Institutes of Health, Bethesda, MD, USA. ${ }^{5}$ Department of Medical Laboratory Science and Biotechnology, China Medical University, Taichung, Taiwan. ${ }^{6}$ Biostatistics Center, China Medical University, Taichung, Taiwan. 
${ }^{7}$ Biostatistics Center, Taipei Medical University, Taipei, Taiwan. ${ }^{8}$ Institute of Biomedical Sciences, Academia Sinica, Taipei, Taiwan. ${ }^{9}$ The Laboratory of Molecular Immunogenetics, National Institute of Allergy and Infectious Diseases, National Institutes of Health, Bethesda, MD, USA. ${ }^{10}$ Viral Biochemistry Section, Laboratory of Molecular Microbiology, National Institute of Allergy and Infectious Diseases, National Institutes of Health, Bethesda, MD, USA. ${ }^{11}$ Asia University, Taichung, Taiwan.

Received: 27 June 2013 Accepted: 9 October 2013

Published: 22 November 2013

\section{References}

1. Burns JC, Glode MP: Kawasaki syndrome. Lancet 2004, 364(9433):533-544.

2. Kawasaki T: Kawasaki disease: a new disease? Acta Paediatr Taiwan 2001, 42(1):8-10.

3. Chang LY, Chang IS, Lu CY, Chiang BL, Lee CY, Chen PJ, Wang JT, Ho HN, Chen DS, Huang LM: Epidemiologic features of Kawasaki disease in Taiwan, 1996-2002. Pediatrics 2004, 114(6):e678-682.

4. Lin YJ, Wan L, Wu JY, Sheu JJ, Lin CW, Lan YC, Lai CH, Hung CH, Tsai Y, Tsai $\mathrm{CH}$, et al: HLA-E gene polymorphism associated with susceptibility to Kawasaki disease and formation of coronary artery aneurysms. Arthritis Rheum 2009, 60(2):604-610.

5. Kato H, Sugimura T, Akagi T, Sato N, Hashino K, Maeno Y, Kazue T, Eto G, Yamakawa R: Long-term consequences of Kawasaki disease. A 10- to 21 year follow-up study of 594 patients. Circulation 1996, 94(6):1379-1385.

6. Gitiaux C, Kossorotoff M, Bergounioux J, Adjadj E, Lesage F, Boddaert N, Hully M, Brugel D, Desguerre I, Bader-Meunier B: Cerebral vasculitis in severe Kawasaki disease: early detection by magnetic resonance imaging and good outcome after intensive treatment. Dev Med Child Neurol 2012, 54(12):1160-1163.

7. lannetti L, Zito R, Bruschi S, Papetti L, Ulgiati F, Nicita F, Del Balzo F, Spalice A: Recent understanding on diagnosis and management of central nervous system vasculitis in children. Clin Dev Immunol 2012, 2012:698327.

8. Takanashi J, Shirai K, Sugawara Y, Okamoto Y, Obonai T, Terada H: Kawasaki disease complicated by mild encephalopathy with a reversible splenial lesion (MERS). J Neurol Sci 2012, 315(1-2):167-169.

9. Worby CA, Dixon JE: Sorting out the cellular functions of sorting nexins. Nat Rev Mol Cell Biol 2002, 3(12):919-931.

10. Hao X, Wang Y, Ren F, Zhu S, Ren Y, Jia B, Li YP, Shi Y, Chang Z: SNX25 regulates TGF-beta signaling by enhancing the receptor degradation. Cell Signal 2011, 23(5):935-946.

11. Cheever ML, Sato TK, de Beer T, Kutateladze TG, Emr SD, Overduin M: Phox domain interaction with Ptdlns(3)P targets the Vam7 t-SNARE to vacuole membranes. Nat Cell Biol 2001, 3(7):613-618.

12. Kanai F, Liu H, Field SJ, Akbary H, Matsuo T, Brown GE, Cantley LC, Yaffe MB: The PX domains of p47phox and p40phox bind to lipid products of PI(3)K Nat Cell Biol 2001, 3(7):675-678.

13. Carlton J, Bujny M, Rutherford A, Cullen P: Sorting nexins-unifying trends and new perspectives. Traffic 2005, 6(2):75-82.

14. Ara S, Kikuchi T, Matsumiya H, Kojima T, Kubo T, Ye RC, Sato A, Kon S, Honma T, Asakura K, et al: Sorting nexin 5 of a new diagnostic marker of papillary thyroid carcinoma regulates Caspase-2. Cancer Sci 2012, 103(7):1356-1362

15. Williams R, Schluter T, Roberts MS, Knauth P, Bohnensack R, Cutler DF: Sorting nexin 17 accelerates internalization yet retards degradation of P-selectin. Mol Biol Cell 2004, 15(7):3095-3105.

16. Le Blanc I, Luyet PP, Pons V, Ferguson C, Emans N, Petiot A, Mayran N, Demaurex N, Faure J, Sadoul R, et al: Endosome-to-cytosol transport of viral nucleocapsids. Nat Cell Biol 2005, 7(7):653-664.

17. Nanbo A, Imai M, Watanabe S, Noda T, Takahashi K, Neumann G, Halfmann $P$, Kawaoka Y: Ebolavirus is internalized into host cells via macropinocytosis in a viral glycoprotein-dependent manner. PLoS Pathog 2010, 6(9):e1001121.

18. Bergant M, Banks L:SNX17 facilitates infection with diverse papillomavirus types. J Virol 2013, 87(2):1270-1273.

19. Schobel S, Neumann S, Hertweck M, Dislich B, Kuhn PH, Kremmer E, Seed B, Baumeister R, Haass C, Lichtenthaler SF: A novel sorting nexin modulates endocytic trafficking and alpha-secretase cleavage of the amyloid precursor protein. J Biol Chem 2008, 283(21):14257-14268.
20. Lin $Y$ J, Lan $Y C$, Hung $C H$, Lin TH, Huang SM, Liao CC, Lin CW, Lai CH, Tien N, Liu X, et al: Variants in ZNRD1 Gene Predict HIV-1/AIDS Disease Progression in a Han Chinese Population in Taiwan. PLOS One 2013, 8(7):e67572.

21. Newburger JW, Takahashi M, Gerber MA, Gewitz MH, Tani LY, Burns JC, Shulman ST, Bolger AF, Ferrieri P, Baltimore RS, et al: Diagnosis, treatment, and long-term management of Kawasaki disease: a statement for health professionals from the Committee on Rheumatic Fever, Endocarditis, and Kawasaki Disease, Council on Cardiovascular Disease in the Young. American Heart Association. Pediatrics 2004, 114(6):1708-1733.

22. Callinan LS, Tabnak F, Holman RC, Maddox RA, Kim JJ, Schonberger LB, Vugia DJ, Belay ED: Kawasaki syndrome and factors associated with coronary artery abnormalities in California. Pediatr Infect Dis J 2012, 31(9):894-898

23. Mitani Y, Sawada H, Hayakawa H, Aoki K, Ohashi H, Matsumura M, Kuroe K Shimpo H, Nakano M, Komada Y: Elevated levels of high-sensitivity C-reactive protein and serum amyloid-A late after Kawasaki disease: association between inflammation and late coronary sequelae in Kawasaki disease. Circulation 2005, 111(1):38-43.

24. Cheung YF, Ho MH, Tam SC, Yung TC: Increased high sensitivity C reactive protein concentrations and increased arterial stiffness in children with a history of Kawasaki disease. Heart 2004, 90(11):1281-1285.

25. Kim T, Choi W, Woo CW, Choi B, Lee J, Lee K, Son C, Lee J: Predictive risk factors for coronary artery abnormalities in Kawasaki disease. Eur J Pediatr 2007, 166(5):421-425.

26. Fernandez-Pisonero I, Duenas Al, Barreiro O, Montero O, Sanchez-Madrid F, Garcia-Rodriguez C: Lipopolysaccharide and sphingosine-1-phosphate cooperate to induce inflammatory molecules and leukocyte adhesion in endothelial cells. J Immunol 2012, 189(11):5402-5410.

27. Rose AB: Intron-mediated regulation of gene expression. Curr Top Microbiol Immunol 2008, 326:277-290

28. Buratti $E$, Baralle FE: Influence of RNA secondary structure on the pre-mRNA splicing process. Mol Cell Biol 2004, 24(24):10505-10514.

29. Varani L, Hasegawa M, Spillantini MG, Smith MJ, Murrell JR, Ghetti B, Klug A, Goedert M, Varani G: Structure of tau exon 10 splicing regulatory element RNA and destabilization by mutations of frontotemporal dementia and parkinsonism linked to chromosome 17. Proc Natl Acad Sci U S A 1999, 96(14):8229-8234.

30. Wright PK, May FE, Darby S, Saif R, Lennard TW, Westley BR: Estrogen regulates vesicle trafficking gene expression in EFF-3, EFM-19 and MCF-7 breast cancer cells. Int I Clin Exp Pathol 2009, 2(5):463-475.

31. Florian V, Schluter T, Bohnensack R: A new member of the sorting nexin family interacts with the C-terminus of P-selectin. Biochem Biophys Res Commun 2001, 281(4):1045-1050

32. Adachi $H$, Tsujimoto $M$ : Adaptor protein sorting nexin 17 interacts with the scavenger receptor FEEL-1/stabilin-1 and modulates its expression on the cell surface. Biochim Biophys Acta 2010, 1803(5):553-563.

33. Czubayko M, Knauth P, Schluter T, Florian V, Bohnensack R: Sorting nexin 17, a non-self-assembling and a Ptdlns(3)P high class affinity protein, interacts with the cerebral cavernous malformation related protein KRIT1. Biochem Biophys Res Commun 2006, 345(3):1264-1272.

34. Falcini F: Kawasaki disease. Curr Opin Rheumatol 2006, 18(1):33-38.

35. Kim S, Dedeoglu F: Update on pediatric vasculitis. Curr Opin Pediatr 2005, 17(6):695-702

36. Wu SF, Chang JS, Wan L, Tsai CH, Tsai FJ: Association of IL-1Ra gene polymorphism, but no association of IL-1beta and IL-4 gene polymorphisms, with Kawasaki disease. J Clin Lab Anal 2005, 19(3):99-102.

37. Wu SF, Chang JS, Peng CT, Shi YR, Tsai FJ: Polymorphism of angiotensin-1 converting enzyme gene and Kawasaki disease. Pediatr Cardiol 2004, 25(5):529-533

38. Akagi T, Rose V, Benson LN, Newman A, Freedom RM: Outcome of coronary artery aneurysms after Kawasaki disease. J Pediatr 1992, 121(5 Pt 1):689-694.

39. Sherry ST, Ward MH, Kholodov M, Baker J, Phan L, Smigielski EM, Sirotkin K dbSNP: the NCBI database of genetic variation. Nucleic Acids Res 2001, 29(1):308-311

40. Sherry ST, Ward M, Sirotkin K: Use of molecular variation in the NCBI dbSNP database. Hum Mutat 2000, 15(1):68-75.

41. Barrett JC, Fry B, Maller J, Daly MJ: Haploview: analysis and visualization of LD and haplotype maps. Bioinformatics 2005, 21(2):263-265. 
42. Tindall EA, Petersen DC, Nikolaysen S, Miller W, Schuster SC, Hayes VM: Interpretation of custom designed Illumina genotype cluster plots for targeted association studies and next-generation sequence validation. BMC Res Notes 2010, 3:39.

43. Gabriel SB, Schaffner SF, Nguyen H, Moore JM, Roy J, Blumenstiel B, Higgins J, DeFelice M, Lochner A, Faggart M, et al: The structure of haplotype blocks in the human genome. Science 2002, 296(5576):2225-2229.

44. Lin WY, Liu HP, Chang JS, Lin YJ: Genetic variations within the PSORS1 region affect Kawasaki disease development and coronary artery aneurysm formation. BioMedicine 2013, 3(2):73-81.

doi:10.1186/2045-3701-3-44

Cite this article as: Lin et al:: Sorting nexin 24 genetic variation associates with coronary artery aneurysm severity in Kawasaki disease patients. Cell \& Bioscience 2013 3:44.

Submit your next manuscript to BioMed Central and take full advantage of:

- Convenient online submission

- Thorough peer review

- No space constraints or color figure charges

- Immediate publication on acceptance

- Inclusion in PubMed, CAS, Scopus and Google Scholar

- Research which is freely available for redistribution 